\title{
La Elegía de la Derrota Anónima
}

(Pablo Guevara: Mi padre, un zapatero)

Por ARMANDO F. ZUBIZARRETA

No. No es don Rodrigo, el Maestro de Santiago, segundo Cid de España. Es, a duras penas, un insignificante zapatero peruano. Claras hazañas de la frontera y al servicio de Castilla, tampoco. La faena cotidiana del taller, el mundo del trabajo y la diversión, en cambio. No es ya Manrique, el indiscutible paradigma de virtudes, vivo resumen de arquetipos clásicos, que ingresa, entre apasionadosencomios, a morar en la galería de la fama; no es quien ipueda, $\mathrm{COB}_{2}$ su vida y muerte ejemplares, marcar el irrebatible contrapunto ético a la trágica serie de los representantes de la concupiscencia humana, derrotados por una Fortuna implacable. Es un humilde artesano, pobre como muchos, que, de su oscura lucha cuerpo a cuerpo con la vida, de su historia de prosperidad y decadencia, apenas emerge como sujeto discutible, librado al juicio y la maledicencia de amigos y familiares.

No es en Ocaña, donde la muerte reta al caballero y donde el sereno tránsito del héroe -que consciente en su morir y que, conservados todos sus sentidos, muere rodeado de los suyos-, nos deja harto consuelo con su memoria. Es en un barrio sin nombre, en una ciudad gris, donde fracasa la vida con un último gesto desesperado. Es el punto final del abandono de un hombre cualquiera: el desamparo, la soledad, la afrentosa sanción del olvido.

Letras, Lima, 40 (80-81): 60-70, 1968. 
La emoción lírica no se vierte en una elegía gravemente acompasada para cincelar la semblanza moral de un claro varón de Castilla, ejemplar de las más nobles aspiraciones de ia sociedad española del siglo XV, donde el testimonio del confiado amor filial de Jorge Manrique se alza, transfigurado, en una reflexión sobre la caducidad de los bienes humanos. La elegía, ahora, se hace cargo de la angustia reivindicatoria de un amor filial dolido y pertinaz - patético voto de confianza contra el destino- que procura la comprensión para una vida desgraciada.

En rebelde desacato a las convencionales normas de la excelencia social y ética, desde la íntima experiencia personal de la relación padre-hijo, afirmándose en la raigambre del cariño y la fidelidad, se eleva la voz poética en recuerdo y justificación de la vida y muerte de un zapatero. Rescatar la entrañable memoria del padre, reivindicar su dignidad, recupe. rar el sentido del ambiguo vivir humilde y frustrado. He allí la perspectiva artística que impone la experiencia humana de Pablo Guevara ${ }^{(1)}$ al quehacer poético y he aquí la elegía -leámosla- en que se cumple?

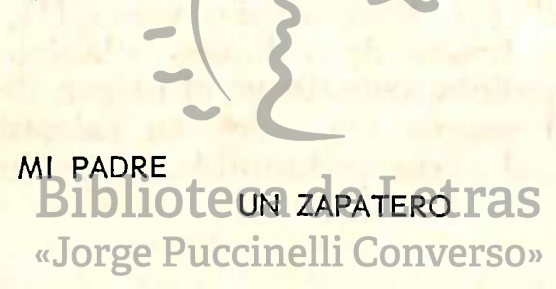

Tenía un gran taller. Era parte del orbe.

Entre cueros y sueños y gritos y zarpazos, él cantaba y cantaba o se ahogaba en la vida. Con Forero y Arteche. Siempre Forero, siempre con Bazetti y mi padre navegando en el patio $y$ el amable licor como un reino sin fin.

Fue bueno, y yo lo supe a pesar de las ruinas que alcancé a acariciar. Fue pobre como muchos, luego creció y creció rodeado de zapatos que luego fueron botas. Gran monarca su oficio, todo creció con él: la casa y mi alcancía y esta humanidad.

(1) No identificamos experiencia humana con autobiografia, aunque, en este caso, pudiera haber una marcada proximidad nitre ambas. 
Pero algo fue muriendo, lentamente al principio:

su fe o su valor, los frágiles trofeos, acaso su pasión;

algo se fue muriendo con esa gran constancia

del que mucho ha deseado.

Y se quedó un día, retorcido en mis brazos,

como una cosa usada, un zapato o un traje,

raíz inolvidable quedó solo y conmigo.

Nadie estaba a su lado. Nadie.

Más allá de la alcoba, amigos y familia,

qué sé yo, lo estrujaban.

Murió solo y conmigo. Nadie se acuerda de él $\left({ }^{2}\right)$.

\section{LA QUEJA: RITMO Y CONSTRUCCION}

Una queja desgarrada, directamente nacida de la congoja filial, desnuda de especial artificio retórico, gobierna el ritmo y la construcción de la elegía: "Murió solo y conmigo. Nadic se acuerda de él" ( $\left.{ }^{3}\right)$. Este último verso $\left({ }^{4}\right)$, llamémoslo así, armado con dos frases de volumen silábico corriente en la lengua diaria española, constituye el origen de la base métrica heptasilábica del poema $\left(^{5}\right)$, de su raigambre popular, en consonancia con el carácter humilde y anónimo del padre derrotado.

(2) El poema, escrito en 1954, aparece en Retorno a la creatura (Madrid, Coopera ción intelectual, 1957), p. 37. La división estrófica, que aparecía en los originales del libro, existe también en un versión primitiva que poseemos (en ade lante nos referiremos a ésta con la abreviatura PR). Hemos reemplazado el punto y coma con que termina el verso 12 con dos puntos.

(3) Guevara había intentado en PR, mediante una ordenación menos coloquial, el segundo heptasílabo: "Nadie de el se acuerda", afortunadamente renunció a tal empeño cuyo resultado era de inferior :alidad

(4) En PR existe un último verso que desapareció en la versión definitiva: "Yo conservo sus lágrimas".

(5) Es posible señalar una base heptasilábica gracias a que en diversas oportunidades la medida escapa a la estructura alejandrina. Los versos 15 y 21 son heptasilabos; tres heptasílabos constituyen $\mathrm{cl}$ verso 13. La estructura de los versos 9-11 supone grupos de siete silabas: $7+7[3 / 4]+7+[4 / 3]+7+7$. Adviértase, sin embargo, que el segundo verso partido por el encabalgamiento ofrece dificultades para la contabilidad por el hecho de la terminacićn aguda antes de la pausa métrica. El verso 19 puede considerarse: $7+2$.

Cabe anotar que en PR existían dos heptasílabos más: "Aunque tanto se ha hablado" (escrito al margen) y el verso tinal "Yo conservo sus lágrimas". 
Pero sería inútil cualquier empeño de devolver a estas frases su tono casero o intrascendente. En la misma medida en que ellas han dado cuerpo y aliento a la elegía, integrantes ya para siempre de un noble alejandrino, han perdido su sencillo aire de prosa y han adquirido dignidad literaria. Gracias a tal encuadre en una arquitectura de versos alejandrinos $\left({ }^{6}\right)$, se ha conseguido el tono heroico que acompaña a la elevación de un insignificante personaje a la categoría de héroe.

Dentro de tal urdimbre métrica, el poeta, dueño y señor de ella, gradúa libremente las transiciones de ritmo entre la solicitación del aliento popular y la del decoro literario (primera estrofa); da sensible representación al dinamismo imaginativo mediante encabalgamientos que quiebran heptasíla. bos adicionales. (segunda estrofa); agrupando tres heptasílabos, sobrepasa con énfasis heroico la medida alejandrina (tercera estrofa); quebrado, por la intensidad emotiva, el ritmo del arte mayor, aisla algunos heptasílabos (tercera y quinta estrofa) y deja, absolutamente fuera de su dúplice esquema métrico, un bisílabo desconsolado y acusador: Nadie (quinta estrofa).

La anécdota de la vida de un zapatero que, entregado al alcohol, se hundió en el fracaso y fue objeto del juicio adverso de los suyos, es reconstruida poéticamente a partir de aquella queja final ya señalada, de amodo que toda la distribución de la materia va aj converger, cada yez menos descriptiva y más íntima y desnuda, en el último verso, concentrando pau. latinamente el pathos de la apasionada reivindicación.

En dos grandes secuencias se reparte la construcción del poema: Vida y muerte del héroe, tres primeras a tres últimas estrofas. La primera secuencia, la vida del héroe, empieza con una primera estrofa descriptiva de la vida habitual del zapatero, de la intensidad de su vivir en el trabajo y la diversión. La segunda y tercera estrofa, subordinadas a esta visión de conjunto, se oponen estableciendo una cierta antinomia de prosperidad y decadencia. La segunda, desde otra perspectiva, contiene como empeño fundamental, el decidido testimonio

(6) Son alejandrinos los versos $1-8,12,14,10-18,20$ y 22; es decir, 15 sobre un total de 22 versos. En PR el verso 4 no alcanzaba a ser todavía un alejandrino: "Forero, Pardo, Arteche. Siempre Forerr,"; alli tambiér, entre los versos escri. tos al margen, aparecía otro alejandrino: "Solo yo conocía de sus canas rasgadas". 
justificatorio de la bondad radical del padre y la tercera intenta, complementariamente, una explicación de la motivación intima de su abandono, de su decadencia. Hasta allí, la vida ha requerido amplias estrofas que, si bien disminuyen, paso a paso, de volumen, van intensificando, en orden inverso, su tono testimonial, de justificación. La segunda secuencia del poema, que se hace cargo del tema de la muerte del héroe, establece un esquema opuesto al anterior, disminuyendo también cada vez más el volumen de las estrofas. La cuarta estrofa presenta la miserable muerte del héroe derrotado en brazos de su hijo $y$, antitéticamente, la estrofa quinta muestra la incomprensión, el injusto desamparo moral por parte de amigos y familiares. La sexta y última estrofa, de un solo verso, constituye la queja del hijo, su protesta de adhesión a la memoria paterna, ofreciendo, en apretada antítesis, la contra. dicción de las dos estrofas anteriores.

Al término de la elegía, se ha hecho nuestra la queja dei poeta, su fervor reivindicatorio de la dignidad del padre.

\section{EL RESCATE DEL HEROE}

Pero no basta con un tono ni con un diseño constructivo. Hace falta algo más para protestar contra la injusticia del olvido, para levantar la imagen deun hombre que acredite el llanto.

En el horizonte de la memoria llena de ternura y comprensión de un niño es donde aparece, como en un mundo de maravilla, de cuento, el taller del humilde zapatero, su oficio, los frutos del trabajo. La elegía empieza por convocarnos, desde las pupilas de la memoria infantil, al recinto de un gran taller que se integra en un espacio cósmico: "Tenía un gran taller. Era parte del orbe". Y nos hace asistir a la mágica prosperidad que crece desmesuradamente: "luego creció y creció rodeado de zapatos que luego / fueron botas". $Y$ nos obliga a admirar, con infantil complacencia, al regio personaje, "gran Monarca en su oficio", por quien todo se incrementa en el hogar.

Juglar de aquel mundo, Pablo Guevara conserva intacta, con cuidadosa cautela, las imágenes infantiles y, al mismo tiempo, les presta vigilante compañía con la madura y sincera mirada del hombre, armonizando la visión maravillada, 
cósmica y mágica del niño con la humanísima comprensión del mayor. Así extiende la dignificación señalada aun a los aspectos más endebles del mundo del artesano ("y el amabie licor como un reino sin fin"), puntualiza la estrecha realidad en la que acontece el milagro de la prosperidad ("fue po. bre como muchos") y culmina la enumeración de las cosas incrementadas ("la casa y mi alcancía" habían sido ofrecidas por el niño) con su propia persona, entregada al recuento en cuerpo entero, en su concreta existencia de carne y hueso ("y esta humanidad"), en vigorosa afirmación del decidido vitalismo del autor.

Gracias a esta fidelidad a sí mismo, a la experiencia infantil y a la raigambre proletaria, el sujeto de la memoria familiar se transfigura en el héroe de aquella humilde epopeya del oficio, la voz lírica adquiere un temple épico de canto al trabajo y es posible rescatar al artesano para que sea personalidad constitutıva de la tragedia que llora la elegía: la irreparable frustración y pérdida de lo que no debió ser roto por el destino, de lo que no debió morir.

\section{EN LA DIMENSION DEL MITO}

Taller de inverosímiles dimensiones cósmicas, conmovedora intensidad de una existencia dionisíaca, sonriente acorde popular entremezclado que presta un aire diario al mito y fresco respiro al pasmo. Todo ello en la primera estrofa encargada de ofrecer, con la cayudaCdelsus imperfectos verbales, el cuadro de la vida habitual del zapatero: su taller, su trabajo, su temple, su fraternal !ibación acostumbrada. Triunfo de la fe en la transfiguración literaria, envés del escepticismo empeñado en avulgarar el mito, y, al mismo tiempo, triunfo de una poderosa convicción íntima del valor universal de la humilde realidad de todos los días.

Por obra y gracia de una adjetivación epitética subjetivo-valorativa ("gran taller") y una precisa selección léxica ("orbe"), dos frases cortas, simplemente enunciativas, construyen para nuestra imaginación el mítico taller del zapatero. En un rápido cambio de ritmo, una enumeración caótica polisindética entremezcla los elementos de la circunstancia en la que se mueve la diaria faena del artesano - los materiales ("cueros"), los psicológicos ("sueños") y los sensoriales ("gritos", "zarpazos") - e inicia la presentación del personzje y su temple. Tal circunstancia ya es tan suya, tan de ve- 
ras unida a su personalidad, que el dentro y el fuera, los objetos y los gestos se confunden en un contorno caracterizador, virtud asegurada por el último término, zarpazos, imagen quizá de su martillear, de su lucha a brazo partido, de tigre, de fiera -fondo armónico de lenguaje popular-, por la vida. Y la intensidad con que aparece este vivir sube de punto en la embriaguez de su optimismo, de su canto esperanzado ("cantaba y cantaba") y en su entrega sin reservas, desesperada ("se ahogaba") a la vida.

Nuevo giro en el ritmo, reemplazo de las frases verbales por las nominales y cambio en la visión. Ahora es el mun. do de amigos en la diversión del artesano, en su evasión por los caminos del alcohol. El vivo contorno humano de los amigos -asegurada la asidua presencia y el movimiento de ellos por la constancia tangible de los nombres y el hábil recurso de la reiteración nominal y adverbial- aparece envuelto por un ritmo cortado y rápido, de sabor popular, que salta por encima de la pausa métrica mediante un encabalgamiento ("siempre / con Bazetti") y que se abre en un largo y pausado compás fina!. Melodía nada extraña en el poeta que inserta versos del vals criollo "El plebeyo", de Felipe Pinglo, en "Riberas del Rímac", poema que pertenece a la misma dirección de esta elegia: "La luz artificial, / con débil proyección / suspendida nos Irae / su miseria como astro" $\left({ }^{7}\right)$.

Pero no es en estal primera estrofa donde el testimonio realista dará una amarga pincelada c La voluntad de dignificar el mundo y la personalidad del padre transfigura también las fiestas del alcohol, el vulgar mar de bebida. Los contertulios aparecen "navegando en el patio", en una travesía poética en la que el "amable licor" - delicada, tierna adjetivación- es "como un reino sin fin". Travesías y reinos que condicen, como un último eslabón, con aquel magistral cuadro de maravilla, donde ninguna estrechez, ninguna miseria impide el canto a la vida, a su aspiración de sueño, a su voluntad de mito.

"En el fondo del corazón, brocados en vez de harapos" es la confidencia reveladora del poeta en su canto a la libertad irreductible $\left({ }^{8}\right)$. Desde allí ha sido proyectado el hermoso mundo consagrado a la memoria del padre.

(7) Retorno a la creatura p. 42.

(8) "El corazón y la Libertad", en Retorno a la creatura p. 32. 
Qué intocable, pero qué lejano el mito y con qué urgen. cia sentimos el tirón de la historia, su imperiosa exígencia de justificación. En la segunda y tercera estrofa de la elegía, la voz del hijo ofrece su apasionado testimonio para justificar la vida del padre y su bondad bienhechora, recorriendo la memoria de la etapa de prosperidad del artesano y su hogar y tratando de salvar, de entre los escombros, una explicación de la decadencia, del fracaso. Nada más cercano a la melodramática actuación del testigo de descargo, vinculado familiarmente al acusado, y, sin embargo, nada más lejos, más liberado por el arte, de la afrentosa condición de tópico.

Con qué voz estremecida, que apenas cabe en la distribución de los heptasílabos. atestigua el hijo la bondad de su padre $\left({ }^{9}\right)$. El juicio por aelante, tajante y breve; luego la explicación, ahita de ternura, de quien había descubierto u? valor hurgando en las "adorables ruinas" - desolada brisa que hiere el mágico e intenso cuadro anterior. Y como alegato probatorio, encuadrada por la conciencia alerta del mayor que señala la pobreza colectiva como punto de partida, se alza otra vez la visión maravillosa del milagro de la prosperidad del artesano.

El incesante crecimiento del humilde taller - nueva reiteración verbal: "creciótyecreció"-zet se Shace tangible en una hermosa y eficaz aunque ilógica $y_{\text {y }}$ arbitraria, imagen dinámica: "rodeado de zapatos que luego / fueron botas", donde con arte de prestidigitación, el vuelco del encabalgamiento, que aprovecha la fracción de un heptasílabo adicional, sirve a la inverosímil metamorfos:s mágica de los zapatos en botas. De inmediato, retomando la temática de la fantasía no. biliaria, muy de cuento infantil, el oficio se convierte en un monarca. $\mathrm{Y}$ terminan por confundirse padre $\mathrm{y}$ oficio, ennoblecida la figura paterna y personalizado el oficio $\left({ }^{10}\right)$, cuando aparecen identificados, a vueltas del encabalgamiento (nue..

(9) En el hemistiquio "Fue bueno, y yo lo supe", el sentido de la frase obliga a respetar la pausa de la coma y es necesario hacer sinalefa y yo, aprovechando la condición poco semiconsonántica de la y limeña. En el primer hemistiquio del verso 16: "Y se quedó un día", el sentido obliga a evitar la sinalefa.

(10) En PR aparecía: "Gran monarca, su oficio también creció/ con él.... "Algunas anotaciones demuestran que el poeta pensó después cambiar el orden: Gran mo. narca, tamblén creció su oficlo / con cl. En la versión definitiva vence la acer. tada identificación que hemos señalado. 
vo heptasílabo suplementario: "todo creció / con él"), en un pronombre que intensifica la visión del benefactor Rey Mago por quien crece la casa y la alcancía - pupila de niño- y el hijo mismo. Con qué singular tono grave, de verdad, se completan las siete sílabas finales en que culmina la segunda estrofa para dar lugar a la presencia, en cuerpo entero, del hijo, testimonio último y primero de la bondad bienhechora del padre y su oficio, mediante un uso popular de concreto vigor plástico: "y esta humanidad" (11).

Pero no es suficiente. ¿Cómo explicar el fracaso, baldón insoslayable? La quinta estrofa intenta escudriñar en la oscura fuerza del destino. Acaso fue la incontenible muerte de su fe, de su valor, de sus satisfacciones efímeras ("frágiles trofeos", en léxico y construcción mantiene la dignificación establecida), la pasión del hombre. Buscando una causa de ruina dig. na del héroe, el poeta, en su ciega y porfiada esperanza, rompiendo la construcción alejandrina, amplía la secuencia heroica del verso con la acumulación de tres heptasílabos. Porque no se consigue determinar la causa, se reitera la frase "algo se fue muriendo" que, con su ambiguiedad, crea el clima angustioso de la estrofa, carga de indefinida angustia que hace más patética la catástrofe y que amenaza ahogar la justificación intentada. Pero una terca intuición llega a la certeza salvadora: "algo se fue muriendo con esa gran constancia / de] que mucho ha deseado". (12). En el envés de la intensidad de la vida, de la vigorosa ambición, una fuerza similar, digna de! mismo héroe, a su medida exacta, habrá sido la asechanza eficaz del destino implacable. No sabemos qué rostro tiene el absurdo, lo ignoramos, pero sentimos el agobio tangible del peso de su mano iniusta y el último heptasílabo, prosaico $y$ gris, quebrado nie con aue concluve la estrofa, se hace cargn de nuestra desolación, de nuestro fatigado empeño de descubrir el secreto del fracaso y de nuestro ánimo apesadumbrado por la evidencia de un duro destino trágico.

\section{EL INJUSTO DESAMPARO FINAL}

En la segunda secuencia del poema el lenguaje se hace escueto, directo, casi por completo desprovisto de imágenes, y adquiere un tono gris, un acre sabor de desgarrón íntimo y sin

(11) El senticio obliga a lee:: yes-ta=hu-ma-ni-dad.

(12) El español familiar de la península y el limeño permiten la sinéresis ca. 
consuelo, a la manera del neorrealismo cinematográfico, crudo y desolado. Sus tres estrofas, de muy pocos versos, narran la mísera muerte del padre - cuarta estrofa-, describen su soledad y humillante desamparo afrentoso - quinta estrofa- ; prestan un último lugar - sexta estrofa - a la atormentada voz del hijo que, a solas con su soledad, reclama por el recuerdo del padre. Nada, sino la soledad de la catástrofe, su amargo clima y la protesta de amor parecen sobrevivir en la elegía.

Desconcertante, absurdo punto final en la cuarta estrofa, la afrenta de la muerte para aquel vivir intenso: "Retorcido en mis brazos, / como una cosa usada, un zapato o un traje". Apenas ebrio garabato, inmóvil para siempre, el zapatero es el trasto inservible - usado, consumido- al que las comparaciones -zapatos sin andanza, traje abandonado- devuelven a su humilde universo y arrumban en un último rincón desvencijado. Una sola imagen, sólo una, común y gastada, recupera aliento y redime aquella visión epiléptica y ridícula del padre retorcido, humano fundamento que, a pesar de la muerte, perdura, y ya sin mengua, en la intimidad del hijo: "Raíz inolvidable, quedó sólo y conmigo".

En el cuadro antitético y complementario de la quinta estrofa pesa la memoria de la última soledad, del abandono: "Nadie estaba a su lado. Nadie"; la dolida reiteración del indeterminado nadie, termina rompiendo, inusitado bisílabo, la configuración métrica del poema, para insistir como enérgico índice acusador. Laríntima tortura del hijo aturdido por la inconcebible actitud de amigos y familiares logra intensificada expresión en el "qué sé yo" y el hiriente recuerdo de la incomprensión, en el patético estrujar que traduce literalmente el sentido de "maledicencia" que tiene la voz popular rajar $\left({ }^{13}\right)$.

A solas con el recuerdo del padre y con su voluntad de reivindicación, origen de la elegía $\mathrm{v}$ término de la composición, el poeta concluye, en la última estrcfa - un solo verso apenas--con la amarga verdad: "Murió solo y conmigo. Nadie se acuerda de él", experiencia dolorosa, terrible contradicción que, forjada por la injusticia, ha desatado el lamento. Y por el en-

(13) La incomprensién familiar y la adhesión del hijo tienen otros testimonios: Los versos escritos al margen de PR ("Aunque tanto se ha hablado sólo yo conocía de sus canas rasgada") y el último verso también desaparecido ("Yo conservo sus lágrimas"). 
vés del final queda sugerido un último verso no escrito: Sólo yo lo recuerdo, infinita soledad de la angustia, incomunicable de por sí $\left.{ }^{14}\right)$. Pero el poema está cumplido: hemos hecho nuestro, gracias a la elegía, un voto contra el destino adverso, ha sido redimida la entrañable figura del zapatero, salvados su hogar y su oficio, reivindicada su vida de héroe anónimo que no debió sepultarse en el fracaso, que merece la comprensión y el llanto.

Porque Mi padre, un zapatero, de Pablo Guevara, ha proclamado la dignidad de un anónımo ser derrotado, porque tal poema resiste el enfrentamiento a las exigencias de un venerable antecedente de prestigio indiscutible y porque autor y poema nos han permitido participar en su justicia $y$, de algún modo, convalidar una íntima emoción nuestra, sabemos que esa página es ya, sin reserva alguna, clásica, irremplazable compañía de hoy y de mañana.

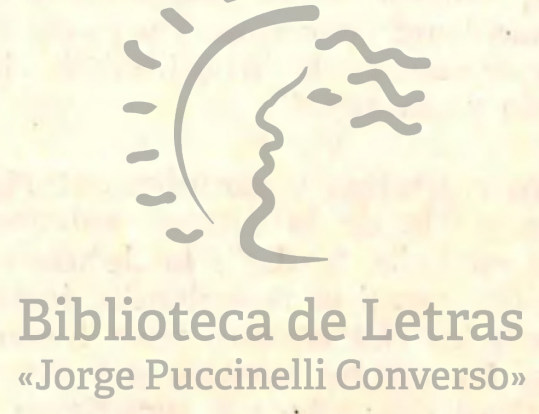

(14) Creemos encontrar justificación para afirmar que el poema concluye con un verso callado, implícito, no escrito, en $e_{1}$ último verso de la redacción primitiva, PR; "Yo conservo sus lágrimas", que ócsaparecić en la versión definitiva. Tal verso, que pretendía romper un silencio intensamente depresivo, resultaba insuficiente traducción literaria de la angustia incomunicable directamente. 